\title{
A Autoconsciência na Teoria de Aron Gurwitsch: Posição e Crítica
}

\author{
Pedro Henrique Santos Decanini Marangoni* \\ Universidade Estadual Paulista Júlio de Mesquita Filho - Unesp/FCL, Assis, SP, Brasil \\ ORCID: https://orcid.org/0000-0002-2473-4514 \\ Danilo Saretta Verissimo** \\ Universidade Estadual Paulista Júlio de Mesquita Filho - Unesp/FCL, Assis, SP, Brasil \\ ORCID: https://orcid.org/0000-0002-7981-3877
}

\begin{abstract}
RESUMO
O objetivo do presente trabalho é apresentar e discutir o modo como o filósofo lituano Aron Gurwitsch concebe o papel da autoconsciência (self-awareness) e da autoconsciência corporal (bodily self-awareness) no interior de sua teoria do campo de consciência. Em um primeiro momento, apresentamos as dimensões do campo de consciência realçando os princípios organizacionais que estão em jogo na integração entre as diferentes estruturas da experiência consciente. Esta contextualização permite compreender a posição ocupada pela autoconsciência naquilo que o filósofo denomina de "margem" da consciência, domínio da experiência caracterizado pela "irrelevância" ou indiferença em relação à apresentação temática - do objeto da atenção. Em um segundo momento, concentrar-nos-emos em descrever a autoconsciência da dimensão encarnada da existência, com o propósito de avaliar os critérios que permitem a Gurwitsch qualificar a autoconsciência corporal sob a rubrica do conceito de "irrelevância". Ao final, esboçamos certos questionamentos à posição de Gurwitsch desenhados a partir de críticas contemporâneas da fenomenologia e das ciências cognitivas à abordagem do autor.
\end{abstract}

Palavras-chave: Aron Gurwitsch, Autoconsciência, Consciência Marginal, Campo de consciência.

\section{Self-awareness in Aron Gurwitsch's Theory: Position and Criticism}

\begin{abstract}
The aim of this paper is to present and discuss how the Lithuanian philosopher Aron Gurwitsch conceives the role of self-awareness and bodily self-awareness within his theory of the field of consciousness. At first, we present the dimensions of the field of consciousness highlighting the organizational principles that are at stake in the integration between the different structures of conscious experience. This contextualization allows us to understand the position occupied by self-awareness in what the philosopher calls the "margin" of consciousness, a domain of experience characterized by "irrelevance" or indifference in relation to the thematic presentation - of the object of attention. In a second step, we will focus on describing the self-awareness of the embodied dimension of existence, with the
\end{abstract}


purpose of evaluating the criteria that allow Gurwitsch to qualify bodily self-awareness under the rubric of the concept of "irrelevance". In the end, we outline an alternative to Gurwitsch's position drawn from contemporary criticisms of phenomenology and cognitive sciences to the author's approach.

Keywords: Aron Gurwitsch, self-awareness, marginal consciousness, field of consciousness.

\section{Autoconciencia en la Teoría de Aron Gurwitsch: Posición y Crítica}

\section{RESUMEN}

El objetivo de este artículo es presentar y discutir cómo el filósofo lituano Aron Gurwitsch concibe el papel de la autoconciencia y la autoconciencia corporal dentro de su teoría del campo de la conciencia. Al principio, presentamos las dimensiones del campo de conciencia destacando los principios organizacionales que están en juego en la integración entre las diferentes estructuras de la experiencia consciente. Esta contextualización nos permite comprender la posición que ocupa la autoconciencia en lo que el filósofo llama el "margen" de la conciencia, un dominio de experiencia caracterizado por la "irrelevancia" o indiferencia en relación con la presentación temática del objeto de atención. En un segundo paso, nos centraremos en describir la autoconciencia de la dimensión encarnada de la existencia, con el propósito de evaluar los criterios que permiten a Gurwitsch calificar la corporeidad bajo la rúbrica del concepto de "irrelevancia". Al final, describimos una alternativa a la posición de Gurwitsch extraída de las críticas contemporáneas de la fenomenología y las ciencias cognitivas al enfoque del autor.

Palabras clave: Aron Gurwitsch, autoconciencia, conciencia marginal, campo de conciencia.

O problema da automanifestação da consciência é central à fenomenologia (Zahavi, 1999). Apesar das inúmeras diferenças conceituais presentes no interior desta tradição, é consenso entre os autores que a autoconsciência é uma estrutura intrínseca da vida consciente. A premissa geral é de que toda consciência de um objeto é, necessariamente, consciência de si mesma, seja por intermédio de uma atividade reflexiva, por meio da qual se tematizam os vividos, seja ainda como manifestação pré-reflexiva e não-temática. O presente trabalho constitui um estudo crítico sobre o problema da autoconsciência na teoria de Aron Gurwitsch. Em um primeiro momento, procedemos por uma breve descrição da organização do campo de consciência, com ênfase naquilo que o filósofo designa como dimensão marginal da consciência. Em uma segunda etapa, passamos à discussão da estrutura e funcionamento da autoconsciência como um elemento integrante da margem da experiência. Em terceiro lugar, mostramos como a autorreferencialidade das experiências se relaciona com o aspecto 
encarnado da existência. Neste ponto, somos conduzidos a uma reflexão sobre a autoconsciência corporal. Por fim, sintetizamos certas posições críticas apresentadas ao longo deste artigo com o objetivo de esboçar o germe de uma contraposição à tese da irrelevância da autoconsciência para a apresentação temática.

\section{O Campo de Consciência}

Aron Gurwitsch (1901-1973) foi um importante intérprete e colaborador da fenomenologia, conhecido por realizar análises exegéticas e de cunho crítico das obras de Husserl. Sua proposta de alargar os horizontes do pensamento fenomenológico se fez, sobretudo, a partir de articulações com a psicologia da Gestalt. Em sua tese de doutoramento, intitulada Fenomenologia da Temática e do Eu puro, Gurwitsch (1929/2009) amplia os limites da teoria da intencionalidade, propondo uma compreensão dinâmica e articulada do campo de consciência, que será desenvolvida em obras posteriores. Segundo Gurwitsch (1957), a consciência apresenta uma estrutura complexa, articulada e tripartite, formada por: tema, campo temático e margem. O primeiro domínio do campo de consciência é o tema, que consiste no centro da atividade consciente. O tema é o objeto sob o foco da atenção, é o correlato noemático de um gênero específico de intencionalidade - a intencionalidade cogitativa ou temática - pela qual os objetos são notados como dados "primários" (Gurwitsch, 1929/2009). O segundo domínio é o contexto temático, o qual compõe o entorno que é "materialmente relevante" ao tema. Para Gurwitsch (1929/2009), toda intenção cogitativa ou temática, que se ocupa de um objeto específico, é permeada por uma espécie de "ambiente noemático", que consiste no "background" pelo qual o objeto temático se destaca (Gurwitsch, 1929/2009). Enquanto escrevo este texto, estou consciente de forma não-temática de uma gama de objetos ou ideias que circunscrevem a operação da escrita. Percebo meu computador ao lado da xícara de café, do abajour, em uma mesa da biblioteca etc. Na percepção do computador, estou também consciente, de modo um pouco menos claro, de minha corrente de ideias, de minhas intenções argumentativas, do meu propósito ao escrever esta parte, do modo como desejo me expressar - enfim, de uma gama de ideias, desejos e memórias que, embora, não sejam objetos espaciais, servem também como contexto para a minha atividade. Não se trata, desta maneira, de levar a cabo uma avaliação que toma a distância espacial como norma para o estabelecimento da função do co-dado, mas sim, uma descrição dos dados co-presentes em sua existência "qualitativa" (Gurwitsch, 1929/2009, p. 218). A pertença do tema ao contexto não é um fato acidental, mas uma necessidade eidética, expressa pelo autor nos 
seguintes termos: "é impossível perceber a coisa sem um ambiente, a coisa simpliciter, apartada de qualquer ambiente" (Gurwitsch, 1929/2009, p. 220). Todo cogito, todo ato de consciência assim como toda cogitatum, todo objeto tal como visado pela consciência, apresentam-se envoltos seja por outros processos mentais, seja por outros objetos - ambos formando o domínio da co-presença.

A teoria de Gurwitsch possui o mérito de delimitar diferenças internas ou modos de organização específicos ao conjunto de dados simultâneos ao tema. Segundo Gurwitsch (1957), o princípio que organiza um determinado setor da dimensão da co-presença é denominado de "relevância material" e refere-se ao modo de estruturação de uma certa ordem de co-dados, caracterizados por estabelecerem uma relação de referência ou implicação direta com o tema. Conforme explana Arvidson (2006, p. 5), "relevância aqui significa que os conteúdos contextuais possuem alguma relação material entre si, tem uma mútua implicação e não são indiferentes uns com os outros". Assim, a demarcação do campo temático no seio do domínio da co-presença advém de sua relevância material ao tema, que consiste em uma espécie de referencialidade vivida entre os itens contextuais e o objeto central. O contexto temático forma o "fundo" sob o qual o tema irá se destacar enquanto "figura". Além disso, o autor defende que os próprios elementos do contexto temático estão intrinsecamente relacionados, contrapondo-se a uma concepção que entende a organização dos elementos contextuais de modo tão somente aditivo, isto é, em uma disposição desprovida de coerência ou referência interna entre os elementos. A descrição deste modelo de "organização" encontraria um modo de relação fundado na expressão: "isto e isto e isto etc." (Gurwitsch, 1929/2009).

Em contrapartida, Gurwitsch entende que entre os elementos do campo temático e o tema há uma conexão gestáltica, caracterizada pela polarização dos conteúdos contextuais em direção ao tema. O autor afirma: "Se um co-dado pertence ou não ao campo temático, como ele está inserido neste campo, qual lugar ele aí ocupa, etc.- tudo depende de sua relação com o tema" (Gurwitsch, 1929/2009, p. 225). Arvidson (2006) descreve o contexto temático como uma articulação de "gestalts não-centralizadas" (non-central gestalts), organizadas entre-si e o tema, o qual ocupa a "gestalt central" (p.6). Portanto, o conceito de relevância elucida a natureza correlacional do vínculo entre campo temático e tema (Gurwitsch, 1929/2009, p.228). Afirmar a "reciprocidade" entre ambos equivale a dizer que sua relação não é meramente temporal, mas que é internamente alimentada pela dinâmica do conjunto.

Há ainda um conjunto de dados co-presentes que não podem ser classificados na categoria do campo temático devido ao estilo unicamente temporal de sua conexão com o 
tema. Trata-se da última dimensão do campo de consciência, a qual o filósofo nomeia como margem (Gurwitsch, 1957). Os conteúdos marginais são os dados que não participam "materialmente" da relação entre tema e contexto temático como, por exemplo, tudo aquilo que está atrás de mim enquanto escrevo este texto, a situação política de meu país ou as casas de minha rua. Estes são dados co-presentes ao processo temático que, no entanto, não influenciariam de forma alguma a relação de pertinência entre tema e contexto (Gurwitsch, 1985/2010). Nessa medida, Gurwitsch (1929/2009) entende que a natureza da relação entre margem e tema é, meramente, temporal - ambos os conjuntos de dados são apreendidos simultaneamente pela consciência, sem que haja qualquer tipo de referencialidade ou conexão intrínseca entre eles. Para o autor, "enquanto que as alterações no campo temático afetam o modo de presentação do tema, nenhuma alteração no tema resulta de mudanças dos dados marginais" (Gurwitsch, 1985/2010, p. 447). Considerando que a relação entre a margem e o contexto temático é extrínseca, o que quer dizer que alterações em um domínio não afetam "materialmente" os conteúdos do outro, Gurwitsch (1985/2010) afirma que não há limite para o número de dados marginais presentes ao campo da consciência. Além disso, o filósofo admite que há apenas um gênero de participação possível dos dados marginais na atividade temática: é pela interferência ou intromissão que aquilo que era dado marginalmente afeta bruscamente a configuração temática (Gurwitsch, 1985/2010).

Para o autor (1985/2010), o caráter dinâmico do campo de consciência, atestado por todo tipo de transformações atencionais, deve-se à presença sempre constante de dados relativos ao nosso fluxo de consciência, à nossa existência encarnada, e ao mundo circundante. Toda a vida da consciência pressupõe a consciência marginal de, ao menos, um desses itens (Gurwitsch, 1985/2010). Enquanto caminho até o supermercado, estou imerso em pensamentos relativos à minha pesquisa, a sua bibliografia, planejamento e execução. Neste contexto de preocupações acadêmicas, posso elencar determinados temas que especificam minha atividade, como os argumentos que utilizarei para compor determinada parte de meu texto. Há uma relação intrínseca entre os argumentos que procuro e o contexto filosófico/acadêmico que torna possível seu relevo para mim. Esta cena, porém, não exclui a manifestação de todo um conjunto de dados que formam uma espécie de horizonte exterior para meu contexto temático. Os carros que passam na rua, as irregularidades da calçada que me obrigam a manobras quase imperceptíveis, as conversas de pessoas que passam, a própria temporalidade do meu fluxo de pensamentos, o fato de que estou andando em determinada direção etc. Uma infinidade de manifestações referentes ao mundo percebido, a meu fluxo de consciência e a minha corporeidade se apresentam marginalmente no campo da consciência. 
Todos estes dados marginais são, segundo Gurwitsch (1985/2010), "irrelevantes” para os pensamentos dos quais me ocupo. A irrelevância material, em contraposição à relevância, é, precisamente, a conceptualização do modo de organização da margem. Além de ser uma dimensão de irrelevância, Gurwitsch qualifica a margem como um "domínio de contingência" (Gurwitsch, 1985/2010). A contingência não se refere a uma suposta dinâmica de aparecimento e esvanecimento da consciência marginal, um vai-e-vem ocasional; esta, pelo contrário, não desaparece jamais. Por contingência, deve-se entender a constante alternância dos conteúdos marginais. A irrelevância é "material" justamente na medida em que os conteúdos marginais não influenciam a apresentação dos conteúdos temáticos e contextuais. Estas três "ordens de existência" da margem (fluxo de consciência, a existência encarnada e o mundo percebido) são dotadas daquilo que Gurwitsch chama de "privilégio da omnipresença" (Gurwitsch, 1985/2010, p. 494). Quer dizer que em toda a experiência temática, estas ordens estão marginalmente presentes e são visadas de forma quase vaga e indistinta pela consciência marginal. É a consciência marginal destas fontes, segundo Gurwitsch (1985/2010), que assegura nossa crença na existência do mundo e em nossa pertença inconteste a ele. Conforme esclarece o autor:

É graças à consciência marginal e à sua estrutura invariante que nós não perdemos jamais de vista a realidade, que nós não perdemos jamais o contato com ela, qualquer que seja a direção na qual se dirige nossa atividade temática, e o quão absorvidos possamos estar nessa atividade (Gurwitsch, 1957, pp. 335).

\section{A Autoconsciência como Dimensão Marginal}

Essa apresentação geral do campo de consciência configura o contexto sob o qual será conduzida a discussão sobre a autoconsciência. Neste momento, gostaríamos de mostrar como a autoconsciência é considerada por Gurwitsch um dado marginal e quais são as implicações desta ideia para a compreensão da organização da experiência.

O fluxo de consciência é uma das chamadas "ordens de existência" que compõem a dimensão marginal da consciência. Um dos aspectos essenciais do fluxo de consciência é a presença de uma autorreferencialidade implícita que acompanha toda visada intencional (Gurwitsch, 1985/2010). A consciência de um determinado objeto sempre é acompanhada de uma consciência implícita do próprio ato que visou o objeto. Ao escutarmos uma música, jogarmos futebol ou lermos um livro, não estamos conscientes apenas dos objetos visados 
pela consciência, mas temos a consciência marginal de nossas próprias experiências. Gurwitsch (1985/2010) expressa estas reflexões da seguinte forma: "Todo ato de consciência é acompanhado de uma atenção [awareness] para si mesmo" (p. 451). Para Gurwitsch (1985/2010), supor que seríamos capazes de visar um determinado objeto sem ter a consciência desta visada implicaria ter a consciência do objeto sem um correspondente conhecimento de nossa experiência. Seríamos incapazes de reconhecer nossa identidade no tempo e, consequentemente, não poderíamos refletir sobre nossas vivências.

Para compreender o vínculo entre autoconsciência e intencionalidade temática, devese clarificar a natureza da interação entre o objeto intencional - o tema da visada intencional e a consciência em sua manifestação implícita ou pré-reflexiva. Gurwitsch (1985/2010) postula que "o tema não deriva nenhum traço ou aspecto de sua perspectiva, orientação ou índice posicional etc. da autoconsciência do ato pelo qual é experienciado" (p. 452). Do ponto de vista noemático, cujo acento descritivo repousa no objeto que aparece mais do que sob o ato que enseja o aparecer, a autoconsciência revela-se um dado marginal porquanto não estabelece junto ao tema nenhuma espécie de implicação ou de relação de pertinência. Em poucas palavras, o que está em jogo na citação acima é a ideia de que a autoconsciência não afeta nem o modo de apresentação do tema e tampouco seus conteúdos objetivos. Por outro lado, e aqui retomamos a gênese da imbricação entre consciência e autoconsciência, segundo Gurwitsch (1985/2010) somente há autoconsciência na medida em que um ato consciente exista e, analogamente, a consciência só pode existir enquanto for acompanhada de autoconsciência. A autoconsciência não é apenas o resultado empírico da existência da consciência, ao contrário, ela é uma condição a priori para a existência da consciência; ela é um componente intrínseco e necessário do ato (Gurwitsch, 1985/2010). Toda experiência de algo envolve, necessariamente, algum nível de autorreferência ou de experiência de si, ainda que pré-reflexivo ou marginal.

Gurwitsch (1985/2010) se precavê frente à formulação de que a automanifestação da consciência exigiria um segundo ato paralelo que capacitaria ao primeiro ato seu caractere "autoconsciente", já que, uma tal concepção sucumbiria ao risco de regressão infinita. Se um ato necessita de um segundo ato para torná-lo autoconsciente, consequentemente, este segundo ato necessitaria de um terceiro ato e assim por diante. Por esse motivo deve-se reforçar a ideia de que "a autoconsciência de um ato está implicada neste ato como um componente intrínseco" (Gurwitsch, 1985/2010, p. 452). Gurwitsch nega, portanto, que a autoconsciência seja uma instância superveniente, ou um ato paralelo. A concepção de que autoconsciência é uma estrutura intrínseca da experiência consciente é suficiente para provar 
seu caráter de dado marginal. Ora, se a autoconsciência é uma estrutura intrínseca a todo ato de consciência, logo todo ato de consciência requer a co-presença da autoconsciência, seja na forma reflexiva, como tematização de certos vividos por vividos superiores, ou na forma préreflexiva, como autoconsciência implícita. Esta "omnipresença” é, como vimos, a característica fundamental das ordens de existência que compõem a dimensão marginal. Dissemos também que a autoconsciência satisfaz a condição de irrelevância que caracteriza todo espectro dos dados marginais, pois, embora a autoconsciência seja uma condição para a experiência consciente, ela não afeta diretamente a atividade temática em sua conotação "objetiva" - ela não toca diretamente o sentido daquilo que aparece. Nas palavras de Gurwitsch (1985/2010), “[o] que aparece, tomado em sentido noemático, precisamente e exatamente como aparece, não inclui o fato de sua aparição ou a consciência deste fato entre seus elementos e constituintes" (p. 452). O exame das relações entre o objeto e o ato, e o ato tomado como objeto, revela que a marginalidade da autoconsciência é satisfeita por duas condições: sua irrelevância material no que concerne ao tema e sua omnipresença na vida da consciência.

A tese de que a autoconsciência é um componente intrínseco à consciência não implica, reiteramos, que a reflexão seja o elemento fundante da experiência autoconsciente. A reflexão apresenta uma diferença fundamental em relação à autoconsciência implícita tal como tratada até o momento. Enquanto esta última assume uma modalidade pré-temática e se apresenta como um requisito para a existência de experiência consciente, a reflexão, por sua vez, é uma atividade superveniente, que "tematiza" os atos de consciência, tomando-os como objetos intencionais. Segundo o filósofo: "a reflexão pode ser definida como a tematização e a objetivação dos atos de consciência por outros atos especiais e específicos" (Gurwitsch, 1985/2010, p. 455). A "percepção interna" (inner awareness) que acompanha os atos de consciência e é anterior à apreensão pela reflexão constitui, segundo Gurwitsch (1985/2010), uma "pré-condição" para esta apreensão. Alguma confusão pode surgir do fato de que Gurwitsch (1985/2010), para designar a autoconsciência não-reflexiva, emprega a expressão "inner awareness" (consciência ou percepção interna). A fim de sanar possíveis malentendidos, o próprio autor escreve que "a consciência interna [inner awareness] que temos de cada ato vivido é obviamente não derivada da reflexão" (Gurwitsch, 1985/2010, p. 454).

Todo esse funcionamento autoconsciente, que alimenta a vida da consciência, não seria possível se os atos de consciência não fossem essencialmente fenômenos temporais. De acordo com Gurwitsch (1985/2010), a temporalidade da consciência se constata em dois fatos fundamentais. Primeiramente, o próprio fluxo de consciência manifesta-se como uma 
totalidade temporal, de modo que cada ato no interior do fluxo conserva relações temporais com os atos adjacentes, sejam estas relações de simultaneidade ou de sucessão. Em segundo lugar, cada ato de consciência é, por si só, um fenômeno temporal, persistindo no tempo como uma unidade integrada no fluxo, em uma duração própria. O desenvolvimento temporal do ato não se compara, por exemplo, à repetição sucessiva de uma nota musical. A duração do ato não corresponde à soma de diversas unidades temporais, mas se constitui como uma unidade que se desenvolve de maneira interconectada entre as fases temporais. O que nos interessa dessa discussão é, principalmente, a compreensão de que a estrutura temporal do ato de consciência "está inclusa" na percepção interna do ato - na autoconsciência. "Nossa consciência do desenvolvimento temporal do ato é a mesma que nossa consciência de seu ser experimentado", escreve Gurwitsch (1985/2010, p. 459). Disto decorre a importante ideia de que é a estrutura temporal da autoconsciência a responsável pela identidade da experiência do ato, em toda sua duração (Gurwitsch, 1985/2010). Todavia, uma ressalva deve ser feita: a apreensão temática da duração e da identidade do ato só ocorre sob o modo reflexivo da autoconsciência. $\mathrm{O}$ autor mostra que o acesso ao objeto pelos atos de consciência nos abre à experiência direta do objeto e não de sua identidade no tempo (Gurwitsch, 1985/2010). Essa identidade pode ser tematizada posteriormente, o que não significa que ela se manifeste tematicamente junto com a manifestação do objeto. A variação dos atos de consciência é seguida por uma subsequente percepção interna de que o ato de agora difere do ato anterior, assim "em outras palavras, nós estamos conscientes de passarmos ou de termos passado de um tema a outro" (Gurwitsch, 1985/2010, p. 459).

No âmbito de discussões contemporâneas sobre a autoconsciência, sua circunscrição ao domínio marginal da experiência nos moldes propostos por Gurwitsch é vista como problemática por alguns autores (Natsoulas, 1997a, Zahavi, 1999; De Vignemont, 2004). Mais adiante, ao discutirmos a autoconsciência corporal, apresentaremos críticas subsidiadas pelas ciências cognitivas e pela filosofia da psicologia. Neste momento, deterer-nos-emos em analisar os argumentos que compõem uma "crítica fenomenológica" às formulações de Gurwitsch (1985/2010) sobre a autoconsciência. Seguiremos o exame realizado por Dan Zahavi, em seu livro "Self-awareness and alterity". Em linhas gerais, o autor defende que a definição da autoconsciência como domínio marginal da experiência, encontrada na obra de Gurwitsch, está imbuída de uma confusão fundamental acerca da ontologia da experiência. Trata-se da identificação implícita entre o modo de manifestação dos objetos transcendentais e o modo de doação da consciência a si. Façamos uma breve digressão para reforçar, com um 
exemplo proposto por Zahavi (1999), os princípios da dinâmica do campo de consciência, estipulados por Gurwitsch (1957).

Em uma agradável manhã de domingo decido começar a preparar o almoço. Organizo os utensílios, temperos e ingredientes que serão utilizados e os disponho em cima do balcão da cozinha. Posiciono aí uma tábua para cortar os tomates. Com a faca em mãos, dou início à minha atividade temática. O campo temático, por sua vez, é formado pelos objetos que circundam esta tarefa e que reservam uma relação especial com esta atividade, como as panelas ou os outros temperos que serão adicionados ao prato. Durante minha atividade, sou acometido pela lembrança de meu pai a me ensinar manusear a faca e a cortar os legumes de uma forma mais segura. Esta lembrança me reposiciona em meu afazer; reorganizo minha atividade temática a partir da emergência desta lembrança. Este exemplo trivial ilustra um dos princípios estabelecidos por Gurwitsch (1929/2009) para compreender a articulação do campo de consciência. Este princípio afirma que a referencialidade entre os componentes do campo temático e o tema não se deixa subsumir à distribuição espacial ou física. A lembrança correlaciona-se intrinsecamente à minha atividade e, portanto, compõe meu campo temático (Zahavi, 1999). Além do campo temático, há uma outra ordem de dados que são simultâneos à atividade temática de cortar tomates e que, entretanto, não são relevantes para a configuração do tema, como é o caso do barulho do motor da geladeira, ou da sensação das meias em meus pés. Poderíamos descrever toda uma paisagem marginal perceptiva, afetiva e cinestésica que envolve as experiências atuais. Há coisas atrás de minhas costas para as quais a consciência não se dirige a não ser de forma vaga, assim como há desejos e lembranças sorrateiras que forram a consciência atual marginalmente. O próprio corpo se apresenta como um campo marginal do qual sou autoconsciente implicitamente - a autoconsciência de cortar os tomates em pé é ligeiramente diferente da autoconsciência de cortá-los sentados. É possível, como vimos, que os dados marginais sejam tematizados - isto é uma possibilidade de essência. Podemos tematizar a sensação de cansaço que sentimos ao permanecermos em pé por muito tempo, tanto como podemos nos voltar ao ruído da geladeira ou para o desejo de ir à praia. Na perspectiva de Gurwitsch parece estar em jogo a ideia de que as experiências marginais, como a sensação das meias em meus pés, estão disponíveis como objetos marginais para os quais a consciência temática pode se dirigir. Podemos "prestar atenção" nestas experiências de maneira análoga à qual podemos tematizar uma música que toca ao fundo de nossa conversa em um café. Tanto as experiências marginais como a música que toca ao fundo são "objetos" marginais. 
É neste ponto que o questionamento de Zahavi (1999) vem à tona. Não haveria, contrariamente ao que está implícito na teoria de Gurwitsch, uma diferença entre a manifestação dos objetos transcendentes e a manifestação da própria consciência? O modo como se vivencia uma sensação, lembrança ou desejo marginal é idêntico ao modo como se manifesta um objeto para a consciência? A pergunta fundamental, para a qual todas as anteriores convergem é: “A condição de possibilidade da manifestação se manifesta?" (Zahavi, 1999, p. 50). É possível conceber a autoconsciência como um objeto que permanece à margem, pronto para ser tematizado, da mesma forma que um outro objeto qualquer, como um chaveiro, por exemplo? Quando se trata da manifestação da consciência para si própria, sua dimensão de autorreferência e autoafetação, será que podemos recobri-la sob o manto da intencionalidade, inferindo que minhas experiências aparecem para mim do mesmo modo que me aparecem os objetos? A problematização dos modos de manifestação da subjetividade e da objetividade indagados de uma perspectiva ontológica revela uma tendência, na filosofia ocidental, em abordar a autorreferencialidade das experiências no âmbito da linguagem da intencionalidade.

Mas, deve-se afirmar tão categoricamente que a estrutura de manifestação da subjetividade também é diádica, no sentido em que envolve a distinção entre um objeto e um sujeito do aparecer? São minhas experiências objetos que aparecem para mim, ou sua fenomenalidade seria radicalmente distinta? A posição adotada por Gurwitsch enquadrar-se-ia nesta tradição ocidental, denominada por Michel Henry de monismo ontológico (Zahavi, 1999). Nesta concepção, a estrutura da autoconsciência é identificada à estrutura da intencionalidade, já que o modo de manifestação da subjetividade é apreendido pelos mesmos parâmetros utilizados para compreensão da manifestação dos objetos. Aplica-se a fórmula diádica do aparecer à própria automanifestação da consciência, o que, de acordo com Zahavi (1999), ignora o aspecto verdadeiramente subjetivo da experiência. Não se distingue o modo de doação em primeira pessoa das experiências do modo de doação dos objetos, fundado no modelo da intencionalidade. Para Zahavi, o acobertamento do modo de doação da subjetividade no interior da lógica da intencionalidade implica pressupor uma cadeia infinita de subjetividades que se manifestam umas às outras. É a mesma lógica utilizada para refutar a pressuposição da autoconsciência como segundo ato superveniente ao primeiro. Além disso, essa estrutura diádica, representada pelo modelo sujeito-objeto, não corresponde à própria ideia de "autoconsciência", segundo a qual se entende que não há uma distinção entre aquilo que se manifesta e o sujeito para quem se manifesta. Conforme explica Zahavi (1999), o problema em se delimitar a autoconsciência pré-reflexiva como um objeto marginal reside, 
especificamente, em equivaler ou identificar a "manifestação" da consciência à manifestação dos objetos para a consciência.

A crítica de Zahavi (1999) possui um valor metodológico central no campo fenomenológico, pois ela se baseia nas nuances do problema da fenomenalidade ou da manifestação. Veremos, na sequência, que o tratamento dado por Gurwitsch (1985/2010) à autoconsciência de nossa existência encarnada propicia a oportunidade de aprofundamento do problema, inclusive a partir de contribuições da filosofia da psicologia e das ciências cognitivas.

\section{A Autoconsciência Corporal e a Organização Temática}

Da caracterização da autoconsciência no interior do fluxo de consciência, rumamos à exposição do polo encarnado da autorreferencialidade de nossas experiências. De acordo com Gurwitsch (1985/2010), a autoconsciência encarnada, ou seja, a percepção de nossas condições posturais, límbicas e gestuais, também se insere na margem do campo de consciência em grande parte do tempo de nossa vida cotidiana. Assim como a autoconsciência é uma estrutura intrínseca dos atos conscientes e, portanto, é uma condição para a existência da consciência, a autoconsciência pré-reflexiva de nossa corporeidade é, nessa medida, omnipresente; ela compõe a própria tessitura do que é a consciência. Além da característica de omnipresença dos dados marginais, inclusive corpóreos, cumpre lembrar outro fator que define a diferença entre itens do campo temático e itens marginais, a saber, o conceito de relevância. Relações de relevância referem-se, conforme Gurwitsch (1985/2010), à intrínseca conexão ou concernimento dos dados co-presentes ao tema.

Segundo Gurwitsch (1985/2010), a consciência pré-temática de ajustamentos posturais é omnipresente a toda atividade temática, mas a autoconsciência destas alterações ou estados corporais não afeta o modo de apresentação do tema. A autoconsciência de nossa situação corporal pode ser tematizada e constituir seu campo temático próprio, quando, por exemplo, nos atentamos para nossa postura, ou tentamos localizar partes de nosso corpo que estão tensionadas etc. É importante observar que a tematização de nossa corporeidade não exclui ou anula a existência do domínio marginal da consciência (Gurwitsch, 1985/2010). Se me atento à minha postura, o que antes era dado como tema, algo em meu campo perceptivo por exemplo, pode tornar-se objeto marginal. Assim, se por um lado a margem é marcada pela omnipresença, por outro, no entanto, os objetos marginais são "desconectados fenomenologicamente" do processo temático (Natsoulas, 1997b), na medida em que não são 
vividos como pertinentes ou como relativos à nossa atividade temática. Desta maneira, para Gurwitsch (1985/2010) a autoconsciência corporal porta o estigma de "mero" concomitante do processo temático, uma vez que seu modo de co-presença se resume ao paralelismo temporal.

Dissemos anteriormente que a consciência de itens contextuais é também concomitante ao processo temático e que, no entanto, a diferença em relação à consciência marginal subjaz no fato de que o contexto é relevante e pertinente ao tema. Em virtude da irrelevância dos dados marginais para a configuração temática, Gurwitsch considera que a autoconsciência de nossas condições corporais se manifesta na forma de "modificações colaterais da consciência”. O autor sublinha a importância e até mesmo a necessária presença da autoconsciência de ajustamentos corporais para a sustentação do processo atencional, embora acrescente que a autoconsciência "não pertença à essência do processo ele mesmo" (Gurwitsch, 1985/2010, p. 483). A omnipresença da autoconsciência corporal, seja ela de nossos ajustamentos posturais, de movimentos ou límbicos, não se apresenta apenas no campo de nossas visadas atuais. Há sempre uma dimensão virtual circunscrita à autoconsciência, relativa a seu funcionamento temporal. Enquanto caminho para a universidade de manhã, tenho autoconsciência virtual de alterar o ritmo de minha passada, de descansar encostado a um muro, ou ainda tenho aberta a possibilidade de carregar minha mochila nas mãos ao invés de carregá-la nas costas. Tanto na autoconsciência atual, como na consciência marginal de possibilidades de deslocamento, nossas experiências cinestésicas são sempre componentes marginais do processo temático. "O fato de adotarmos esta postura ao invés daquela não tem nenhuma influência [has no bearing] sobre a estrutura e a organização do campo perceptivo" (Gurwitsch, 1985/2010, p. 485).

Evidentemente, Gurwitsch reconhece que nossos deslocamentos corporais alteram nossas perspectivas sobre o objeto percebido. A forma como as coisas aparecem na percepção, diz o autor, "depende, em uma certa extensão, da posição de nosso corpo com relação a elas" (Gurwitsch, 1985/2010, p. 486). Apesar de constatar uma relação de correspondência entre a percepção dos objetos e nossas experiências cinestésicas, afinal de contas perceber um prédio de perto e de longe envolve movimentos e sensações corporais distintas, Gurwitsch (1985/2010) sustenta não haver uma relação de “inclusão" de um domínio no outro. Para que se teça essa relação de correspondência, prossegue o autor, é necessário adotarmos uma outra atitude, diferente daquela na qual estamos voltados para o mundo percebido. É por meio desta outra atitude que os dados perceptivos e cinestésicos 
passam a ser tematizados simultaneamente. Essa tematização dos dois conjuntos de dados não é, entretanto, a forma usual de se viver na percepção.

$\mathrm{Na}$ atitude da percepção, a correspondência entre as aparências perceptivas das coisas percebidas e as experiências cinestésicas não é estabelecida e formulada [...] Experiências cinestésicas, tanto atuais como virtuais, acompanham permanentemente o processo perceptivo como concomitantes marginais, mas elas não estão integradas neste processo (Gurwitsch, 1985/2010, pp. 487).

Em uma série de artigos dedicados ao problema da autoconsciência em Gurwitsch e William James, Thomas Natsoulas (1997a; 1997b) argumenta, em contraposição ao primeiro, que a autoconsciência das mudanças cinestésicas é parte essencial do processo temático. $\mathrm{O}$ autor tece algumas importantes objeções à teoria da irrelevância da autoconsciência corporal para o processo temático. Em primeiro lugar, o autor entende que a característica de omnipresença da autoconsciência por si só deveria ser considerada como um dado "relevante". O que está implícito aqui, a nosso ver, é um alargamento do conceito de "relevância", o qual para Natsoulas (1997a) não designa somente a pertinência dos conteúdos materiais entre-si, mas se estende para toda atividade consciente, ainda que a relação entre o tema e os dados marginais seja apenas temporal. A delimitação reflexiva daquilo que se consideraria como relevante é complexa e vaga, haja vista que a relação entre experiência vivida e experiência tematizada não se esgota no movimento que vai da segunda para a primeira. Em segundo lugar, Natsoulas (1997a) assinala que a autoconsciência de nosso fluxo temporal, com suas dimensões antecipatórias e retentivas, desempenha uma função importante na apresentação do tema atual. De acordo com Gurwitsch (1985/2010), a consciência retém marginalmente itens passados que podem ser atualizados, transformando-se em novos temas. Natsoulas (1997a) julga que esta capacidade retentiva está diretamente vinculada ao processo temático, já que a percepção de um tema envolve a consciência marginal retentiva de suas apresentações anteriores.

Gurwitsch (1985/2010) nos fornece um emblemático exemplo de como certos sentimentos ou sensações corporais marginais não influenciam no processo temático. $\mathrm{O}$ autor ilustra a tese da irrelevância da autoconsciência corporal tomando como caso a tentativa de resolução de um problema matemático. Quando pensamos em um certo problema matemático estamos imersos em um certo campo contextual de teorias ou fórmulas matemáticas que incidem diretamente no problema em questão. Ao mesmo tempo, durante a resolução do 
problema, vivenciamos uma diversidade de sensações corporais, que abrangem desde a retenção e o stress, ocasionando o fechamento da glótis e pausas na respiração, até sensações de alívio ao encontrarmos uma resposta - relaxam-se os músculos, respira-se profundamente etc. Para Gurwitsch (1985/2010), estas sensações não interferem de forma alguma no processo de resolução do problema. O tratamento dado ao problema teórico independe da postura que assumimos, ou das modificações corporais que possam ocorrer.

$\mathrm{Na}$ atividade de leitura, por exemplo, estamos marginalmente conscientes de nossa postura, de movimentar nossos olhos e virar as páginas do livro. Cada trecho é lido sob a perspectiva do que se acabou de ler e envolve, também, um certo grau de expectativas sobre o que está por vir. Para Natsoulas (1997a), a autoconsciência relativa a nossos estados de receio ou apreensão acerca do bem-estar de uma personagem, por exemplo, influencia diretamente o modo como apreendemos o conteúdo subsequente. O autor considera que os sentimentos de retenção e alívio são partes essenciais do processo de resolução do problema matemático eles podem nos indicar novas formas de encarar a situação matemática. Por essa razão, Natsoulas (1997b) entende que a autoconsciência destas sensações corporais integra o campo temático e não a margem da consciência. $\mathrm{O}$ autor escreve:

Meu ponto é o de que as sensações corporais de alívio podem estar lá o tempo inteiro como parte do processo temático em evidente relação com o problema; elas podem ser autoconsciência corporal com referência ao problema. Tais sensações corporais são parte do que pretendemos quando dizemos que o problema no qual trabalhamos é difícil (Natsoulas, 1997b, pp. 98, grifos do autor)

No exemplo em apreço, Natsoulas julga que Gurwitsch compreendera a relevância em termos estritamente lógicos, relativos aos passos necessários para a resolução do problema matemático. Esta excessiva atenção à lógica do processo implica, contudo, uma subsequente minimização da importância da "experiência vivida" para a configuração temática, afirma o autor (Natsoulas, 1997b). É importante reiterar que de acordo com Gurwitsch (1985/2010), as mudanças corporais não "pertencem", não integram e, portanto, não alteram o processo temático de solução do problema matemático. Por um lado, Natsoulas (1997b) concorda que não podemos identificar nossas sensações de retenção e alívio como "partes" do problema ele mesmo, mas, por outro, o autor contrapõe-se ao esquema total desta tese sob a prerrogativa de que diversos itens contextuais não podem, ainda que sejam relevantes, ser considerados "partes do problema". Se a diferença entre estes dois domínios de dados, contextuais e 
marginais, reside no conceito de relevância, então soa problemático o discurso de traçar os contornos do que seria ou não relevante apenas em termos lógicos, sem apontar para o suporte psicossomático do processo. Estudos recentes em psicologia cognitiva, que partilham do mesmo gênero de interpretação holística do campo de consciência proposto por Gurwitsch, propõem a tese de que os dados periféricos (marginais) afetam a atividade temática de forma intrínseca (Yoshimi \& Vinson, 2015). Tal hipótese fora testada em experimentos realizados com grupos-controle diversos, em que a realização de uma mesma tarefa temática era marcada pela diferença na introdução de variáveis marginais manipuladas entre os grupos. Eis o caso, por exemplo, de um experimento composto por dois grupos em que a atividade temática consistia em estimar o ângulo de uma rampa, e depois relatá-lo verbalmente (Bhalla \& Proffitt, 1999). Fora solicitado a um dos grupos que seus integrantes portassem mochilas pesadas durante a realização da tarefa, as quais figurariam como variável marginal introduzida pelos pesquisadores, ao passo que no outro grupo não fora inserido nenhum dado marginal controlado. O grupo que carregava as mochilas relatou uma percepção mais íngreme da rampa do que o grupo sem as mochilas, o que pode indicar que a alteração dos dados cinestésicos introduzida pelo peso da mochila teve consequências fundamentais na apresentação perceptiva do objeto.

Outro estudo, desenvolvido por Williams \& Bargh (2008), demonstra que experiências físicas de calor influenciam os sentimentos de "calorosidade" ou receptividade interpessoal de maneira marginal ou não-temática. Os autores idealizaram um experimento que consistia em abordar individualmente os sujeitos da pesquisa em um elevador, de maneira casual, a caminho daquilo que eles julgavam ser o experimento real. O pesquisador "disfarçado" iniciava uma conversa casual no elevador e, em dado momento, pedia gentilmente aos sujeitos que segurassem seu copo de café enquanto organizava suas coisas. Posteriormente, sem o conhecimento prévio de que se tratava de um experimento, fora pedido aos sujeitos que relatassem a percepção da pessoa com quem conversaram. Estes pesquisadores constataram que sujeitos que seguravam copos de café quente durante a conversa tinham maior propensão a perceber ou a julgar a "calorosidade" de uma determinada pessoa, do que sujeitos com copos de café frio. Estes, ao contrário, foram mais propensos a realizar julgamentos neutros ou mesmo negativos. Ambos os experimentos colocam em questão a tese de uma indiferença dos dados marginais e, especificamente dos dados relativos à autoconsciência corporal, frente à apresentação temática. 


\section{Possíveis Encaminhamentos Críticos}

Neste trabalho, buscamos elucidar a função da autoconsciência no interior da teoria de Gurwitsch, com ênfase no modo como o autor constrói os critérios para determiná-la dentro do domínio marginal da consciência. A tese da irrelevância pode ser expressa nos seguintes termos: "Os fatos marginais [...] não contribuem em nada à formação do tema ele mesmo, nem à formação da perspectiva sob o qual este aparece" (Gurwitsch, 2002, p. 150). Em vista do que foi apresentado, esboçamos uma primeira hipótese de trabalho, uma "suspeita teórica" que será desenvolvida em estudos posteriores. Trata-se da ideia de que a teoria da existência encarnada no campo de consciência pode ser expandida para incluir o fato de que os dados marginais relativos à autoconsciência interveem de maneira positiva na organização temática. O desenvolvimento desta hipótese requer o exame detalhado dos princípios de articulação das estruturas do campo, com menção central ao conceito de relevância.

Ao invés de pensarmos que a intervenção marginal seria como uma espécie de “empurrão" em direção a um dado até então não notado a título focal, não poderíamos, por outro lado, considerar que a autoconsciência marginal das condições corporais influencia a perspectiva ou a orientação do tema de uma forma mais sutil, sem uma necessária reestruturação abrupta da atenção? A fadiga e o stress, por exemplo, são estados que filtram o campo de possibilidades de ação em relação ao tema, sem que eles próprios sejam objetos de nossa atenção. Os sentimentos marginais de apreensão que me acompanham em uma tensa partida de xadrez não poderiam influenciar o modo como eu percebo ou valorizo determinadas possibilidades ou setores do tabuleiro? Os sentimentos corporais de apreensão, a inconstância de minha respiração e até mesmo minha postura não são referências intrínsecas ao que está acontecendo no tabuleiro? Não seriam elementos importantes que poderiam influenciar as constantes modificações atencionais que me permitem passear pelo jogo e apreender o máximo de possibilidades?

Recordemos que a função do contexto temático é providenciar uma determinada orientação ou posição ao tema (Gurwitsch, 1929/2009). Imaginar um cavalo correndo em um grande pasto e um cavalo no meio da sua sala de jantar é deparar-se com o mesmo objeto sobre duas perspectivas diferentes. O núcleo noemático do objeto mantém-se o mesmo, seu sentido não se altera - o que se alteram são seus caracteres noemáticos, ou seja, seu modo de apresentação, as diferenças atencionais etc. Ainda assim, o contexto contribui para a circunscrição do sentido em referência a algo que não ele próprio. Seguindo este mesmo caminho, a autoconsciência marginal de nossa existência encarnada parece, e aqui reside 
nossa suspeita, justamente delimitar um outro tipo de perspectiva - não mais fenomenologicamente acessível pela consciência - mas vivida no nível da própria corporeidade.

Estaríamos aqui defendendo a inserção da autoconsciência no contexto temático, à maneira de Natsoulas? Não, pois conforme explica De Vignemont (2004), deve-se preservar a tese da irrelevância dos dados marginais para que se evite admitir que toda experiência corporal está fenomenologicamente relacionada à atividade temática. Uma tal assunção iria em direção contrária ao fato de que o engajamento do corpo no mundo envolve seu necessário auto-esquecimento, sua posição de fundo ou background, o que é condizente com sua condição de dado marginal. Porém, o argumento central pelo qual Gurwitsch assimila a existência encarnada na margem não é, propriamente, a dinamicidade e a fluidez com a qual nos relacionamos e percebemos o ambiente. Novamente, a chave do problema, a nosso ver, está no conceito de relevância e em sua vinculação à experiência da referencialidade.

Um percurso alternativo que nos permite evitar situar as experiências marginais do corpo no contexto temático consiste em reformular a tese acerca da "desconexão fenomenológica" entre dados marginais e atividade temática. Quando Gurwitsch afirma que a autoconsciência de nossa postura ou de nossos gestos não é relevante para um problema matemático que tentamos resolver, sua posição se estabelece em um nível demasiadamente cognitivo. A relevância define o tipo de conexão gestáltica estabelecida entre tema e contexto a partir de um apelo à experiência de pertinência, concernimento ou relação. Neste ponto, os questionamentos de Natsoulas podem ser sintetizados da seguinte forma: como circunscrever, no nível reflexivo, aquilo que fora, de fato, relevante para a apresentação do tema?

A manutenção de uma desconexão fenomenológica, tal como propomos, não é um atestado da irrelevância da corporeidade para o processo temático, é, ao contrário, uma afirmação positiva sobre uma dimensão eminentemente elusiva. A corporeidade não pertence ao campo temático porque ela se situa em um nível mais primordial na organização do sentido percebido. Não consigo acessar e relatar verbalmente as minúcias de meus ajustamentos motores, o que não significa, no entanto, que eles estejam apartados do campo da experiência. Há uma implicação e mesmo uma produção de experiência perceptiva que é propriamente pré-noética e pré-subjetiva (Gallagher, 1995). Por essa razão, é uma experiência que escapa à consciência contextual. Nos dizeres de Shaun Gallagher (1995):

Quando eu percebo, eu não percebo meu corpo realizando os ajustamentos esquemáticos que tanto permitem como moldam o perceber. Eles não aparecem como 
partes explícitas do sentido perceptivo, embora explicitamente eles estruturem esse sentido (Gallagher, 1995, pp. 235)

Poder-se-ia argumentar que essa linha de raciocínio nos conduz, em seu destino final, a assumir que os dados proprioceptivos e cinestésicos, enfim a auto-sensibilidade do corpo, derivam de representações inconscientes que orientam as pequenas particularidades da existência corpórea, como o movimento de meus dedos em direção a um copo de água (De Vignemont, 2004). De acordo com Zahavi (1999), o fato de que não temos uma consciência explícita de todo e qualquer dado proprioceptivo não exclui a existência de alguma consciência destas alterações. Não estou consciente do exato ângulo de minhas pernas, mas há uma auto-sensibilidade geral de minha postura. Nossos corpos formam um sistema de equivalências e adequações pré-reflexivas com o mundo, que produz e ao mesmo tempo delimita as condições de operação da consciência perceptiva. A percepção é investida de valores afetivos e motores que constituem uma espécie de atmosfera prática, relacionada às capacidades e às possibilidades de ação no mundo. Um tipo de relevância anônima, mais fundamental e que é essencialmente ecológica: as coisas me evocam certas ações a partir de minha situação de sujeito encarnado. Essa permeabilidade do corpo com o mundo é suficiente para que o processo temático adquira uma nova luz, que excede as capacidades de apreensão da introspecção sem que sejam postuladas como uma maquinação corporal inconsciente. $\mathrm{O}$ sentido perceptivo emerge nesse acoplamento anônimo e geral entre o corpo, em sua autorreferencialidade, e o leque interno de possibilidades decorrentes do próprio campo percebido. A rampa, no exemplo dos experimentos com dados marginais controlados, é vista como íngreme e não como aterrorizadora, por exemplo, o que indica a inserção do sentido numa malha sensível formada entre corpo e mundo. Nossa interrogação inicial sobre a margem e a autoconsciência na teoria de Gurwitsch nos conduziu à "suspeita", inspirada e alimentada por estudos contemporâneos, de que a autoconsciência corporal é uma estrutura marginal ímpar que não pode nem ser compreendida sob a mesma categoria de relevância imputada aos dados contextuais nem tampouco a partir do conceito de irrelevância em sua denotação de não-pertinência. Esboçamos um primeiro espectro de questões e ideias que necessitam refinamentos teóricos propostos como os próximos passos de nosso trajeto. 


\section{Referências}

Arvidson, P. S. (2006). The Sphere of Attention: Context and Margin. Dordrecht: Springer.

Bhalla, M. \& Proffitt, D. R. (1999). Visual-motor recalibration in geographical slant perception. Journal of Experimental Psychology: Human Perception and Performance, 25(4), 1076-1999. doi:10.1037/0096-1523.25.4.1076

De Vignemont, F. (2004). The Marginal Body. In L. Embree (Ed.), Gurwitsch's Relevancy for Cognitive Sciences (pp. 131-149). Dordrecht: Springer.

Gallagher, S (1995). Body Schema and Intentionality. In J. Bermúdez, A. Marcel, \& N. Eilan (Eds), The Body and the Self (pp. 225-245). Cambridge: MIT Press.

Gurwitsch, A. (1957). Theorie du champ de la conscience. Paris: Desclée de Brouwer.

Gurwitsch, A (2002). Esquisse de la phénoménologie constitutive. Paris: Vrin.

Gurwitsch, A. (2009). Phenomenology of Thematics and of the Pure Ego: Studies of the Relation Between Gestalt Theory and Phenomenology. In F. Kersten (Ed.), The Collected Works of AronGurwitsch (1901-1973): Studies in Phenomenology and Psychology (Vol. 2, pp. 193-317). Dordrecht: Springer. (Obra original publicada em 1929)

Gurwitsch, A. (2010). Marginal Consciousness. In L. Embree, \& R. M. Zaner (Eds.), The Collected Works of Aron Gurwitsch (1901-1973): The Field of Consciousness: Theme, Thematic Field, and Margin (Vol. 3, pp. 13-537). Dordrecht: Springer. (Obra original publicada em 1985)

Natsoulas, T. (1997a). The Stream of Consciousness: XIII: Bodily Self-Awareness and Aron Gurwitsch's Margin. Imagination, Cognition and Personality, 16(3), 281-300. doi:10.2190/E6AF-YB5H-FFM6-7J0F

Natsoulas, T. (1997b). The stream of consciousness XIV: Two contrasting accounts of pervasive bodily self-awareness. Imagination, Cognition and Personality, 17(1), 4564. doi:10.2190/KB74-TK3F-MH78-5JFV

Williams, L. E., \& Bargh, J. A. (2008). Experiencing physical warmth promotes interpersonal warmth. Science (New York, N.Y.), 322(5901), 606-607. doi:0.1126/science.1162548

Yoshimi, J., \& Vinson, D. W. (2015). Extending Gurwitsch's field theory of consciousness. Consciousness and cognition: An International Journal, 34, 104-123. doi:10.1016/j.concog.2015.03.017

Zahavi, D. (1999). Self-awareness and alterity: A phenomenological investigation. Evanston: Northwestern University Press. 


\section{Endereço para correspondência}

\section{Pedro Henrique Santos Decanini Marangoni}

Rua Dr. Ranimiro Lotufo, 593 apto 34, Botucatu - SP, Brasil. CEP 18606-770

Endereço eletrônico: pedro.marangoni@yahoo.com.br

\section{Danilo Saretta Verissimo}

Universidade Estadual Paulista Júlio de Mesquita Filho

Faculdade de Ciências e Letras de Assis - Departamento de Psicologia Social e Educacional

Av. Dom Antônio, 2100, Parque Universitário, Assis - SP, Brasil. CEP 19806-900

Endereço eletrônico: danilo.verissimo@gmail.com

Recebido em: 05/07/2020

Aceito em: 04/09/2020

\section{Notas}

* Doutorando em Psicologia pela Universidade Estadual Paulista (UNESP), Faculdade de Ciências e Letras de Assis.

** Docente do Departamento de Psicologia Social e Educacional e do PPG em Psicologia - Universidade Estadual Paulista (UNESP).

Financiamento: A pesquisa relatada no manuscrito foi financiada pela bolsa de doutorado do primeiro autor (FAPESP, No. Processo 2017-15348-3).

Este artigo de revista Estudos e Pesquisas em Psicologia é licenciado sob uma Licença Creative Commons Atribuição-Não Comercial 3.0 Não Adaptada. 